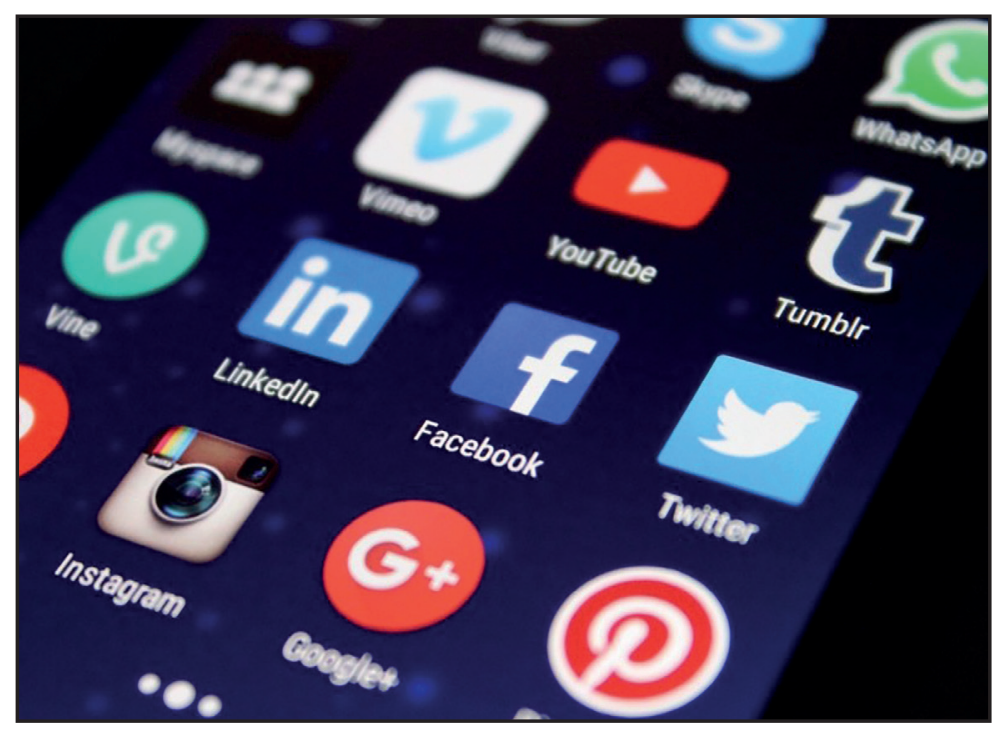

\title{
DEMOCRACIA Y REDES SOCIALES
}

Piedra Cardoso, Jorge

Correspondencia: tomebamba@gmail.com 


\title{
Resumen:
}

La Internet ha traído grandes beneficios para el desarrollo de los derechos humanos; en especial, la libertad de expresión. A través de las redes sociales, cualquier ciudadano puede opinar sin limitación, en casi todos los países del planeta. Sin embargo, existen excesos de esta libre expresión que están provocando la reacción de varios gobiernos, que piden mayor control y protección a los usuarios.

Palabras clave: Internet, facebook, redes, democracia, libertad.

\section{DEMOCRACY AND SOCIAL NETWORKS}

\begin{abstract}
:
Internet has brought great benefits to the development of human rights; in particular, freedom of expression. Any citizen in almost every country on the planet can give an opinion through social networks without limitation. However, there are excesses of this free expression that are provoking the reaction of several governments, who demand greater control and protection from users.
\end{abstract}

Keywords: Internet, Facebook, networks, democracy, freedom. 
"Las redes sociales le dan el derecho de hablar a legiones de idiotas que primero hablaban sólo en el bar después de un vaso de vino, sin dañar a la comunidad. Ellos eran silenciados rápidamente y ahora tienen el mismo derecho a hablar que un premio Nobel. Es la invasión de los idiotas" Umberto Eco (La Stampa, junio de 2015).

La democracia es la expresión de la voluntad de los pueblos a través de sus gobernantes. Esto solo ocurre en sociedades en las que impera el Estado de Derecho, es decir, el sometimiento a una legalidad constituida; por lo tanto, no se puede hablar de ella en un Estado dictatorial.

Es esencial a la democracia un modelo de pesos y contrapesos, una necesaria y saludable división de poderes planteada por Montesquieu hace más de tres siglos, en donde cada una de estas funciones cumpla su rol y vigile a las otras. Así ha venido funcionando el modelo occidental desde los tiempos de la Revolución Francesa.

\section{Los medios de comunicación tradicionales ante la popularización de las redes sociales}

La televisión, y no la prensa o la radio, ha tenido una influencia más determinante en la decisión de las sociedades democráticas a la hora de acercarse a las urnas. Un estudio de 1987 de los investigadores Inyengar y Kinder, reseñado por Giovanni Sartori en su libro "Homo Videns, la sociedad teledirigida", concluyó que "las noticias 
televisivas influyen de un modo decisivo en las prioridades atribuidas por las personas a los problemas nacionales y las consideraciones, según las cuales, valoran a los dirigentes políticos"; en otras palabras, las noticias transmitidas por la televisión tienen la capacidad de modificar los índices de valoración del público hacia sus electores y gobernantes.

En la televisión vemos personas en lugar de discursos o programas de partidos políticos. "En sus tiempos, Hitler, Mussolini y Perón se las arreglaron perfectamente con la radio, los noticiarios proyectados en los cines y los comicios", (Sartori en 'Homo Videns'). Así fue hasta que llegó la televisión, en la que el personaje es el mensaje: "la política -en imágenes- se fundamenta en la exhibición de personas.

Con la masificación de la Internet, ¿puede volverse obsoleta la televisión? El televisor emite imágenes para un espectador pasivo que lo mira, mientras que el ciberespacio es un mundo interactivo, con usuarios dinámicos. Entonces, se puede decir que ninguno será excluido por el otro, porque son medios diferentes. Otro asunto será determinar quién ganará más importancia.

A través de Internet se transmiten imágenes, vídeo, audio, texto e información de todo tipo y, lo más importante, se permite el diálogo entre los usuarios y su opinión de los contenidos que publican los medios en la web.

Sartori se preguntó hace veinte años si Internet producirá un crecimiento cultural entre los seres humanos. En teoría esto debería ser así, la cuestión es que el niño que vivió en los años noventa y en la primera década de este siglo y que se inició con la televisión, su interés 
cognoscitivo no está sensibilizado para la abstracción; "Internet podría ayudar a que este homo videns ya formado con la televisión salga de ese mundo de imágenes". Y así ha ocurrido en gran medida con los millennials, generación nacida entre los años ochenta y la década pasada, que en gran medida no recuerdan como era el mundo sin Internet.

Los niños de hoy, entre 5 y 15 años de edad, dedican 15 horas a la semana a Internet ( 78 minutos más que el año anterior), señala un estudio de 2016 de Ofcom, autoridad de gobierno reguladora de las telecomunicaciones y servicios postales del Reino Unido. Mientras tanto, los tiempos de consumo de televisión han caído de 14 horas 48 minutos en 2015 a 13 horas 36 minutos en 2016 (72 minutos menos). ¿Qué consumen en el ciberespacio los niños británicos?: el $73 \%$ son usuarios periódicos de YouTube. Se marca una tendencia en la que la televisión no tiene un futuro sencillo, reseña la publicación Puro Márketing.

Los datos del estudio del consumo del Global Web Indec en redes sociales en el cuarto trimestre del año anterior, publicados en la web Clases de Periodismo, el 3 de diciembre de 2016, son reveladores:

- El 94\% de los adultos online tiene una cuenta en al menos una red social. Además, casi todos los usuarios de internet han visitado o usado una red social en el último mes. Los números revelan que los usuarios más jóvenes y los mercados en crecimiento son los que destacan.

- El $42 \%$ de los usuarios se conecta a redes sociales para conversar con amigos, y el 39\% revisa las noticias. Las principales motivaciones son pasivas e involucran a otros usuarios que son los que publican el contenido. 
- Al menos 4 de cada 10 siguen a sus marcas favoritas en redes sociales y al menos 3 de cada 10 usuarios da follow a medios de comunicación.

- Los consumidores digitales están gastando en promedio una hora y 58 minutos por día en redes sociales y mensajería instantánea. Es decir, las redes involucran 1 de cada 3 minutos en línea. Las cifras más altas están entre 16 y 24 años.

- En los 31 mercados analizados, el tiempo invertido en línea se ha elevado. En los mercados emergentes hay más actividades largas en conexión en comparación con América del Norte o Europa.

\section{Redes sociales en el Ecuador}

El 22 de febrero de 2017, la web Formación Gerencial presentó un estudio del consumo de redes sociales en el Ecuador, en el que se destaca que ya son más de 13 millones de usuarios de Internet. "El comportamiento del ecuatoriano en medios digitales está centrado en la búsqueda, consumo de video, noticias, transacciones y redes sociales, evolucionando día a día hacia la generación de contenido y consumo de alternativas locales que complementan la oferta internacional, siendo cada vez más adepto a la generación de transacciones en comercio electrónico y servicios".

Google y YouTube son las direcciones de entrada a la navegación en el Ecuador, según la clasificación de Alexa, una subsidiaria de la compañía Amazon.com con sede en California que proporciona datos y análisis comerciales de tráfico web. 
En cuanto a la utilización de redes sociales en el Ecuador, Facebook lidera la lista con once millones de usuarios registrados, de los cuales, seis millones y medio acceden al menos una vez al mes. Luego vienen Instagram, Linkedin y Twitter. Todas estas redes son utilizadas principalmente desde dispositivos móviles.

\section{Internet: usual herramienta para difundir falsedades, difamaciones y engaños}

Al menos el $82 \%$ de los alumnos no puede distinguir entre "contenido patrocinado" y una noticia real en una página web, precisa un estudio de la Universidad de Stanford a 7.804 estudiantes, publicado en la web Clases de Periodismo el 23 de noviembre de 2016.

La investigación, citada por The Wall Street Journal, determina que muchos de los estudiantes consideraron la credibilidad de las noticias solo por tener una foto, y no por la fuente.

Por ejemplo, dos de cada tres alumnos que no pudieron encontrar alguna razón válida para desconfiar de un post escrito por un ejecutivo de banco argumentaron que los adultos jóvenes necesitan más ayuda en planificación financiera.

Y casi cuatro de cada 10 estudiantes de secundaria creen, basándose en el título, que una foto de margaritas deformadas son una fuerte evidencia de condiciones tóxicas cerca de la planta nuclear de Fukushima Daiichi en Japón, a pesar de que no hay ninguna fuente o ubicación para la foto. 
De otro lado, el $88 \%$ de jóvenes revisa noticias desde Facebook y otras redes sociales, según un estudio en 2015 a 1.045 adultos de entre 18 y 34 años. Ese informe fue realizado por el Proyecto Insight Media.

\section{El caso \#LadyTantra}

Mientras se desarrollaba con normalidad la celebración del Día de la Mujer, el pasado 8 de marzo se hizo viral un vídeo grabado por un marido que descubrió a su esposa engañándole. La filmó saliendo de un motel en Quito con otro hombre; en el vídeo ella se baja del auto y le pide a su esposo que deje de filmarla. Alguien publicó el vídeo en la red y a través de la Internet, éste llegó a cuantos dispositivos y personas pudo, su alcance fue tan grande que habría de llegar a los medios de comunicación más importantes del mundo como noticia.

No solo se compartió el vídeo; posteriormente se empezaron a publicar las fotografías del hombre con su esposa, con su hijo, contrayendo matrimonio, de vacaciones, etc. Se hicieron centenares de imágenes y vídeos de burla, más conocidos como "memes" en los que además se atacó con palabras violentas a la mujer por haber engañado a su marido.

En pocas horas el hashtag \#LadyTantra que hacía referencia al vídeo por el nombre del motel en el que ella fue filmada, era tendencia nacional en las redes sociales más populares del Ecuador. La "revelación" llegó tan lejos que una cuenta internacional de Twitter de uno de los grandes medios de comunicación ecuatoriano (Ecuavisa Internacional) compartió una nota con los "memes» de 
\#LadyTantra. Pocas horas después, borró esa publicación ofreciendo sus sinceras disculpas.

Pasadas las once de la noche del Día de la Mujer, algunos usuarios de la red incluso llegaron a compartir el número de celular de \#LadyTantra con sus nombres y apellidos, la gente comentaba en esta fotografía diciendo que "ya le enviaron un mensaje", se reían y animaban a los usuarios de la red para que también le enviaran sus opiniones a esta mujer.

Dentro de las conversaciones cotidianas en el trabajo, en el gimnasio, en la calle, más de uno hizo la pregunta "¿ya viste el vídeo de la mujer infiel?", y si el otro respondía que no, el primero le enviaba en ese momento el vídeo. Grupos enteros conversaron del caso, dando sus perspectivas y opiniones, siendo la gran mayoría de ellas, insultos. Incluso circulaba una imagen en Facebook que decía "Si no te llegó el vídeo de la infiel, significa que no tienes buenos grupos de WhatsApp", haciendo alusión a que éste había llegado a los ojos o dispositivos de todo el Ecuador.

El morbo y amarillismo fueron el alimento de los ecuatorianos durante un día entero, el ocho de marzo. Las mismas personas que en la mañana felicitaban a la mujer como "la más hermosa creación de la tierra", durante la tarde del mismo día, habrían de señalar a \#LadyTantra con insultos y humillaciones.

Tras una oleada de agravios, de manera eventual, la reflexión y autocrítica llegó con varias opiniones y comentarios. Una usuaria de la red social Twitter comentó: "lo que se comenta en redes sociales en el caso 
\#LadyTantra refleja una sociedad inquisidora del siglo XIV con tecnología del siglo XXI". Al siguiente día de la lapidación a \#LadyTantra, los comentarios de difamación fueron poco a poco reemplazándose por silencios y críticas a quienes habían apedreado con palabras a esta mujer.

Luego de una semana de lo sucedido, muy pocos hablaron de este nuevo episodio de difamación a través de las redes sociales, mientras la mayoría retomó el tema coyuntural de la política electoral. Las páginas de Internet, en donde se compartieron esos contenidos, como "El Mercioco", borraron el vídeo.

El ex presidente uruguayo, José Mujica, dice acerca de las redes sociales: "a veces las redes son el nido de los cobardes que no dan la cara".

\section{Legislar y judicializar las redes sociales}

Ante la serie de bulos y ataques a la intimidad de las personas que se diseminan a manera de noticias, Alemania plantea imponer multas de hasta 50 millones de euros a las compañías detrás de las redes sociales que no eliminen contenido relacionado con discurso de odio, contenido ilegal y por último contenido falsificado con motivos políticos, más conocido como "noticias falsas", publica el periódico La Vanguardia el 15 de marzo de 2017.

De su lado, el creador y CEO de Facebook, Mark Zuckerberg ha admitido y lamentado que "la desinformación es un gran asunto" en su red. Asimismo, ha desmentido la teoría según la cual a Facebook le benefician las noticias falsas por lo que implicarían más tráfico de usuarios y avalancha de clics.

306 
Desde hace unos días la red social mantiene activa para un grupo de usuarios la posibilidad de incluir una bandera o una etiqueta roja con un signo de exclamación junto a las noticias de veracidad dudosa. Cuando varios usuarios las señalen con ese símbolo, estas son enviadas a supervisores externos de verificación de datos con los que Facebook ha llegado a acuerdos, como ABC News, Associated Press, FactCheck.org, Politifact and Snopes.

Las noticias o páginas que no pasen el fact check (comprobación de datos) se podrán ver, pero serán marcadas públicamente como "cuestionada por comprobadores externos". Si hacen clic en ese vínculo, los internautas podrán saber por qué su veracidad está en cuestión. Además, estas historias se relegarán a puestos secundarios en el newsfeed (listado de noticias).

También se trabaja en diferenciar las noticias que son compartidas por los usuarios después de leer solo el titular y aquellas que son compartidas después de leer el texto completo, ya que esto último puede ser un indicativo de que el relato es coherente.

Tanto Facebook como Twitter tienen plataformas y medidas establecidas para colaborar con las autoridades de cada país, dentro de los marcos legales. El gobierno alemán lamenta que tan solo "el $1 \%$ de las peticiones que hacemos a Twitter acaban en contenido borrado", para Facebook esa cifra es del $39 \%$. 


\section{La libre expresión y la democracia en las redes sociales}

La libertad de divulgar información de manera instantánea por parte de cualquier ciudadano es una de las máximas expresiones de la democracia, pero con los excesos que están ocurriendo en Internet, el mundo se avecina a proyectar una regulación que frene el libertinaje que domina en el ciberespacio.

En el Ecuador, el Código Orgánico Integral Penal (COIP), las leyes de propiedad intelectual y las normas de telecomunicaciones son las herramientas con las que se puede sancionar el comportamiento de los cibernautas. Juan Carlos Solines, abogado especialista en derechos digitales, explicó el 4 de abril de 2016 en diario El Comercio, que existe un esquema utilizado por los gobiernos para restringir la libertad de expresión e información en Internet. "Sus tres fases son: bloquear las redes o determinado sitio web, desarrollar una legislación para intervenir y tener influencia en los flujos de información y el ataque directo".

La norma que ahora resulta más efectiva es la penal tipificada en el artículo 396 del Código Orgánico Integral Penal, COIP ("Será sancionada con pena privativa de libertad de quince a treinta días la persona que, por cualquier medio, profiera expresiones en descrédito o deshonra en contra de otra").

Cuando ocurren casos de invasión a la privacidad e intimidad de las personas con su consiguiente difusión en las redes sociales como el de \#LadyTantra, el COIP tipifica en el artículo 178 lo siguiente: "La persona que, sin contar 
con el consentimiento o la autorización legal, acceda, intercepte, examine, retenga, grabe, reproduzca, difunda o publique datos personales, mensajes de datos, voz, audio y vídeo, objetos postales, información contenida en soportes informáticos, comunicaciones privadas o reservadas de otra persona por cualquier medio, será sancionada con pena privativa de libertad de uno a tres años".

Otras formas de sancionar las publicaciones por redes sociales es a través de las leyes de propiedad intelectual internacionales. En el Ecuador, ha sido el gobierno y su movimiento político PAIS el que ha acudido a la empresa española Ares Rights, para dar de baja los contenidos porque las imágenes utilizadas pertenecen generalmente a la Presidencia de la República o a Alianza País. Por ejemplo, informa El Comercio, en abril de 2014 le sucedió a la cuenta de la tuitera Diana Amores por haber publicado el logo del oficialismo.

A esto se suma la Ley de Telecomunicaciones, que dicta, en su artículo 22, que la autoridad competente podrá, entre otros, limitar o bloquear los contenidos o acceso a Internet de los usuarios.

\section{Reflexiones finales}

Es preocupante que los ciudadanos se informan, o eso creen, cada día más a través de las redes sociales. El problema está en que lo hacen sin diferenciar cuál es la fuente. La información está diluida en el boca a boca y eso no garantiza que estemos mejor comunicados. "Los errores, falsedades, inexactitudes de las redes no inducen a tomarse las cosas con más calma, sino a verificar con 
la mayor rapidez", establece Miguel Ángel Bastenier, periodista, articulista y profesor de la Escuela de Diario El País.

La mentira en las redes sociales se combate con buen periodismo -sobre todo-, buenas prácticas y el código penal. No hay más recetas, opina Bastenier. "Vivimos una inundación comunicativo-informativa en la que lo más fácil es chapotear en lugar de mantener la cabeza fuera del agua. Ante la inundación 〈viral〉 de presuntos sucedidos, debemos saber seleccionar hoy más que nunca y despreciar lo que no es genuino".

"En el mundo digital, los medios tradicionales han encontrado en las redes sociales un aliado indispensable. Como compañías dedicadas a la distribución global de información, Googley Facebooktienen nuevasobligaciones. Ya no son solo meras plataformas tecnológicas. De la misma manera que vetan determinados contenidos, ya sean mensajes de odio o imágenes de desnudos, deben velar porque las noticias que albergan sean veraces. Establecer cortafuegos ante las webs mentirosas no significa abrir la puerta a la censura" (Mentiras y redes sociales, El País, 18 de noviembre de 2016).

Volvemos a Umberto Eco para resaltar un punto destacable de las redes sociales: «el fenómeno de Twitter es por una parte positivo, pensemos en China o en Erdogan. Hay quien llega a sostener que Auschwitz no habría sido posible con Internet, porque la noticia se habría difundido viralmente. Pero por otra parte, da derecho de palabra a legiones de imbéciles» (Universidad de Turín, junio de 2015). Asimismo, hay que reconocer que, a veces, las redes sociales, aunque caóticas y poco reflexivas, se 
convierten en fuentes primarias y valiosas de información a la que no llegan los medios tradicionales.

Otro asunto es el de las formas, algo que no es secundario. ¿Cómo se escribe en las redes sociales? Muchas veces como una transcripción apresurada de un pensamiento lleno de abreviaturas, con eliminación de signos ortográficos, escritura fonética, entre otros artificios que le restan calidad y credibilidad a la información. Dejamos en claro que esta es una obligación por remediar, porque somos lo que escribimos aún más que lo que hablamos.

El otro gran reto, cuyos resultados se empiezan a ver, es convertir a una multitud pasiva y mediocre en una multitud activa e inteligente. Y lo más importante: no porque las redes sociales se han convertido en los medios de comunicación más plurales y democráticos que los demás, la responsabilidad ética deba convertirse en un accesorio de la comunicación.

\section{Bibliografía:}

- Giovanni Sartori, Homo Videns, la sociedad teledirigida, 2013, Prisa Ediciones, decimoquinta reimpresión. México.

- Rafael Rodríguez Prieto / Fernando Martínez Cabezudo, Poder e Internet, un análisis crítico de la red, 2016, Ediciones Cátedra, Madrid, España. 